Situs Jurnal : $\underline{\text { http://ejournal.stiepancasetia.ac.id/index.php/jieb }}$

Jilid 5 Nomor 3 November 2019

Hal $344-352$

\title{
KAJIAN PEMBERDAYAAN SUMBER DAYA MANUSIA DALAM UPAYA MENGOPTIMALKAN POTENSI HUMAN CAPITAL PADA PT. CARSURIN DI BANJARBARU
}

\section{Riris Ambarwati*}

Abstract: This study aims to examine and know the empowerment of human resources at PT. CARSURIN. This research is a qualitative research with case study approach. The research subjects were 15 employees at PT. CARSURIN Banjarbaru. The data were collected through interviews, observations, and made a review of documents. The analysis shows that the dimension of empowerment that has been implemented well is the motivation and decision making, the dimension being done but still need improvement is the belief, the weakest dimension and more attention needs is the stagnant dimension of mind-sets. it was also found that the company has considerable Human capital potential, the dimension of knowledge and ability, the dimension being done but still requires efforts that can optimize the potential, in the field of expertise and skills.

\section{Keywords: Empowerment of Human Resources, Human capital, empowerment}

Abstrak: Penelitian ini bertujuan untuk mengkaji dan mengetahui pemberdayaan sumber daya manusia pada PT. CARSURIN. Penelitian ini merupakan penelitian kualitatif dengan pendekatan studi kasus. Subjek penelitian 15 karyawan di PT. CARSURIN Banjarbaru. Pengumpulan data dilakukan melalui wawancara, pengamatan, serta membuat telaah dokumen. Hasil analisis menunjukkan bahwa dimensi pemberdayaan yang telah diimplementasikan dengan baik adalah motivasi dan pengambilan keputusan, dimensi yang sedang dilakukan namun masih perlu peningkatan adalah kepercayaan, dimensi yang paling lemah serta perlu mendapat perhatian lebih adalah dimensi stagnan mind-sets. Ditemukan juga bahwa perusahaan memiliki potensi Human capital yang cukup besar, dimensi pengetahuan dan kemampuan, dimensi yang sedang dilakukan namun masih memerlukan upaya-upaya yang dapat mengoptimalkan potensi tersebut, di bidang keahlian dan keterampilan.

Kata kunci: Pemberdayaan Sumber Daya Manusia, Human capital, pemberdayaan

\section{Latar Belakang}

Sumber daya manusia merupakan aset terpenting perusahaan karena perannya sebagai subyek pelaksana kebijakan dan kegiatan operasional perusahaan. Sumber daya yang dimiliki oleh perusahaan seperti modal, metode, dan mesin tidak bisa memberikan hasil yang optimum apabila tidak didukung oleh sumber daya manusia yang mempunyai kinerja yang optimum.

Pemberdayaan karyawan yang dilakukan oleh perusahaan kepada karyawannya dapat memacu untuk meningkatkan kreativitas, motivasi, dan daya inovatif yang dimiliki oleh setiap karyawan dalam melaksanakan tugas dan tanggung jawabnya. Dengan adanya program pemberdayaan sumber daya manusia, diharapkan kinerja karyawan akan meningkat dan tujuan perusahaan akan tercapai. Pemberdayaan sama dengan pendelegasian wewenang ada dua karakteristik yang menjadikan pemberdayaan unik, pertama karyawan didukung untuk 
memakai inisiatif mereka sendiri dan kedua pemberdayaan manusia tidak hanya sebatas memberi otoritas, tetapi juga sumber daya sehingga mereka mampu membuat keputusan dan memiliki kekuasaan untuk di implementasikan.

Menyadari begitu pentingnya sumber daya manusia untuk suatu perusahaan. Pada masa ini baik perusahaan jasa maupun industri manufaktur sedang mengalami tantangan khususnya dalam hal Pemberdayaan Sumber Daya Manusia yang dimiliki. Hal itu terjadi karena kompetensi yang semakin meningkat diantara perusahaan-perusahaan yang kemudian merupakan kompetensi diantara sumber daya manusia yang dimiliki oleh masing-masing perusahaan. Hal itu berarti jika suatu perusahaan menginginkan untuk tetap kompetitif dan memiliki keunggulan dalam bersaing maka dalam pemberdayaan sumber daya manusianya harus memiliki konsep yang tepat.

Pengetahuan karyawan merupakan salah satu elemen penting yang melekat pada karyawan dan hal itu menjadi bagian dari yang disebutkan dalam teori Human capital. Sejalan dengan hal itu, pemberdayaan sumber daya manusia dikaitkan dengan teori atau konsep Human capital diharapkan akan memberikan dampak positif yaitu suatu nilai kompetitif berkelanjutan bagi perusahaan.

Penelitian ini dilakukan di PT. CARSURIN merupakan perusahaan swasta mengkhususkan diri dalam survei independen dan layanan superintending. Sejak awal, PT. CARSURIN terus memperluasan pelayanan jasa lengkapnya sesuai permintaan. Selama 40 tahun PT. CARSURIN telah memperhatian kebutuhan klien dan memiliki sejarah yang membanggakan dalam memberikan layanan yang luar biasa dengan integritas. Dalam prosesnya, budaya bisnis yang unik telah muncul yang mendorong rekan untuk melakukan yang terbaik. Dalam pemberdayaan sumber daya manusianya masih memerlukan suatu pendekatan dan konsep yang tepat. Ada banyak hal yang menarik untuk diteliti atau dikaji lebih mendalam berkaitan dengan pemberdayaan sumber daya manusianya, khususnya untuk mengoptimalkan potensi Human capital yang dimiliki oleh perusahaan.

Dari data dan informasi observasi awal, menunjukan bahwa pihak manajemen atau pimpinan menginginkan sumber daya manusia yang dimiliki bisa ditingkatkan pengetahuan dan keterampilan/keahlian dan semakin diberdayakan, namun hal itu sering terkendala karena berbagai faktor tidak adanya tempat pelatihan dan pengembangan yang tepat/disediakannya tempat pelatihan di sekitar kantor yang tidak menganggu waktu kerja dan bisa dilaksanakan di luar jam kerja atau pada saat libur kerja. Karena kemungkinan adanya sikap malas belajar dari para karyawan, dan penjadwalan waktu yang tepat untuk pelatihan dan pengembangan ilmu agar tidak mengganggu jam kerja kantor. Belum terealisasi dengan baik karena pada kenyataannya pelatihan dilakukan pada jam kerja, dan di ruangan yang cukup kondusif, tetapi tidak memadai. Karena pelatihan/seminar yang sering dilakukan dan bimbingan kerja masingmasing Divisi/Departemen masih dilakukan di jam kerja, secara online yang dilakukan dan dijadwalkan oleh Perusahaan PT. CARSURIN Pusat. Adapun training atau pelatihan yang diikut sertakan oleh perusahaan hanya karyawan tertentu saja yang memang dikhususkan pada posisi tertentu seperti meneliti kadar batu bara. Belum merata pemberdayaan karyawan pada PT. Carsurin Banjarbaru.

Penelitian ini bertujuan untuk mengkaji dan mengetahui pemberdayaan sumber daya manusia dan potensi Human capital pada PT. CARSURIN. Untuk mengkaji dan mengetahui faktor-faktor yang menghambat atau menjadi tantangan dalam pemberdayaan sumber daya manusia di PT. CARSURIN. Serta untuk mengkaji dan mengetahui perbaikan implementasi pemberdayaan sumber daya manusia sehingga mendukung upaya optimalisasi potensi Human capital di PT. CARSURIN. 


\section{Kajian Literatur}

Penelitian Kay Greasley, Alan Briman et al (2008), Dengan pendekatan kualitatif penelitian ini bermaksud untuk melihat berbagai makna pemberdayaan karyawan dari perspektif karyawan itu sendiri, dilihat dari dimensi psikologis. Penelitian yang dilakukan oleh Anyadike, Nkechi O. Dengan judul Human Resource Planning and Employee Productivity Nigeria Public Organitation pada tahun 2013 penelitian ini menekankan pada produktivitas dalam organisasi publik Nigeria telah mengalami penurunan. Penelitian ini bertujuan untuk menyelidiki peran Perencanaan Sumber Daya Manusia (HRP) dalam memastikan produktivitas karyawan dalam Organisasi Masyarakat Nigeria. Metedelogi penelitian ini adalah menggunakan kualitatif dengan mengambil data sekunder seperti dokumen pemerintah, penelitian sebelumnya, analisis pakar, koran, dan majalah. Penelitian yang dilakukan oleh M. Ghilman Adni pada tahun 2013 yang berjudul Perencanaan Sumber Daya Manusia di KBIH Aisyiyah Yogyakarta. Penelitian ini menggunakan metode deskriptif kualitatif. Penelitian ini bertujuan untuk mendeskripsikan dan menganalisa Perencanaan Sumber Daya Manusia di KBIK Aisyiyah Yogyakarta. Dan untuk mengetahui faktor pendukung dan faktor penghambat pada proses perencanaan sumber daya manusia KBIH Aisyiyah.

Penelitian yang dilakukan oleh Indarta Priyana pada tahun 2016 yang berjudul Kajian Pemberdayaan Sumber Daya Manusia dalam Mengoptimalkan Human capital PT. SIMNU di Bandung. Penelitian ini menggunakan deskriptif kualitatif. Penelitian ini bertujuan untuk mendeskripsikan dan menganalisa mengkaji dan mengetahui pemberdayaan sumber daya manusia di PT. SIMNU, mengkaji dan mengetahui Human capital di PT. SIMNU, mengkaji dan mengetahui faktor-faktor yang menghambat atau menjadi tantangan dalam pemberdayaan sumber daya manusia di PT. SIMNU, mengkaji dan mengetahui perbaikan implementasi pemberdayaan sumber daya manusia sehingga mendukung upaya optimalisasi potensi Human capital di PT. SIMNU.

Penelitian yang dilakukan oleh Aleluia Ardina Irmaputri pada tahun 2017 yang berjudul Studi Kualitatif Pemberdayaan Karyawan Pada Perusahaan Bisnis Kreatif. Penelitian ini menggunakan deskriptif kualitatif. Penelitian ini bertujuan untuk memahami pemberdayaan dari sudut karyawan, mengetahui dampak positif yang terjadi dalam pemberdayaan karyawan, mengetahui dampak negatif yang terjadi dalam pemberdayaan karyawan, mengetahui pemberdayaan karyawan bila terjadi konflik di tempat kerja.

\section{Metode Penelitian}

Metodelogi penelitian merupakan pendekatan terhadap penetapan tata cara atau prosedur penelitian yang dilakukan secara tersusun dan sistematik untuk mencapai tujuan penelitian yang dirumuskan. Dalam penelitian kualitatif tidak dikenal istilah variabel, sehingga diperlukan parameter atau ukuran sebagai batasannya. Dalam penelitian ini ada dua tema pokok yang diteliti, yaitu: pemberdayaan sumber daya manusia dan humal capital, yang masing-masing dimensi tersebut dijalankan dalam perusahaan.

Pemberdayaan manusia, parameternya meliputi 4 (empat) hal yaitu: Kepercayaan, Motivasi, Pengembangan Keputusan, Stagnant Mind-sets. Sedangkan Human capital parameternya meliputi : Pengetahuan (Knowledge), Keahlian (Expertise), Kemampuan (Ability), Keterampilan (Skill).

Dalam operasionalisasi parameter, penelitian ini meliputi beberapa aspek yang dapat dijabarkan sebagai berikut:

1. Penelitian dilakukan di perusahaan di mana kegiatan perusahaan berjalan, atau di tempat di mana nara sumber bersedia diwawancarai.

2. Pelaku dan narasumber yang diamati atau untuk diwawancarai adalah Staff Karyawan PT. CARSURIN. 
3. Pengamatan dan wawancara yang dilakukan mengenai pemberdayaan karyawan yang dilakukan oleh perusahaan dan konsep atau pendekatan yang digunakan, dan kaitannya dalam upaya mengoptimalkan potensi Human capital perusahaan.

4. Terbuka dengan semua perkembangan yang terjadi di perusahaan.

\section{Hasil Penelitian}

Hasil penelitian ini berupa berbagai data dan informasi yang telah di kumpulkan baik melalui pengamatan secara langsung, studi dokumen, serta interaksi dan wawancara dengan narasumber. Untuk memberikan gambaran secara jelas mengenai pemberdayaan sumber daya manusia dalam mengoptimalkan Human capital pada PT. CARSURIN. Peneliti melakukan wawancara dengan mengajukan pertanyaan-pertanyaan dalam bentuk pedoman wawancara dengan menggunakan dua parameter yaitu parameter pemberdayaan sumber daya manusia dan Human capital. Kepada narasumber berjumlah 15 orang staff Karyawan yang bekerja di PT. CARSURIN.

Dalam penelitian ini, tipe wawancara yang digunakan adalah semi terstruktur. Tipe wawancara ini dipilih karena kombinasi antara wawancara terstruktur dan wawancara tidak terstruktur sehingga tidak terlalu kaku dan tidak terlalu bebas. Pewawancara sudah menyiapkan daftar pertanyaan panduan wawancara. Daftar pertanyaan pemandu biasanya berfungsi untuk memulai wawancara. Urutan pertanyaan dan pembahasan tidak harus sama seperti pada panduan, tergantung pada kebutuhan pada saat wawancara. Dalam penelitian dengan metode kualitatif ini, peneliti memperoleh data primer dan sekunder dari perusahaan PT. CARSURIN melalui berbagai cara : data primer di dapatkan melalui pengamatan dan wawancara, dan data sekunder di dapatkan dengan melakukan studi dokumen yang salah satunya berupa Struktur Organisasi PT. CARSURIN, serta beberapa pengambilan foto wawancara dengan narasumber maupun foto lokasi penelitian termasuk aktivitas perusahaan. Beberapa data dan informasi juga diperoleh dari kondisi yang alamiah (Natural Setting) dimana peneliti secara langsung melihat dan mengamati kegiatan operasional perusahaan dan melakukan wawancara dengan para karyawan atau pelaku kegiatan operasional.

Pengumpulan data primer dan informasi utama melalui wawancara mendalam (in-depth interview) dengan berbagai narasumber yang diyakini bisa memberikan data dan informasi untuk tujuan penelitian ini. Para narasumber adalah mewakili manajemen puncak (top management) sampai dengan manajemen bawah (bottom management). Adapun daftar narasumber sesuai dengan Tabel 1.

Tabel 1. Narasumber Penelitian

\begin{tabular}{clcccl}
\hline Kode & Nama Karyawan & $\begin{array}{c}\text { Usia } \\
\text { (Tahun) }\end{array}$ & $\begin{array}{c}\text { Jenis Kelamin } \\
(\mathrm{L} / \mathrm{P})\end{array}$ & $\begin{array}{c}\text { Lama } \\
\text { Bekerja }\end{array}$ & Divisi / Departemen \\
\hline 1 & Heru Nugroho & 31 & $\mathrm{~L}$ & 2 Tahun & Finance Accounting \\
\hline 2 & Dwi Utomo & 38 & $\mathrm{~L}$ & 2 Tahun & Operations \\
\hline 3 & Arif Rinsan & 48 & $\mathrm{~L}$ & 16 Tahun & GA \\
\hline 4 & Dina Rosdiyana & 32 & $\mathrm{P}$ & 3 Tahun & Ops - Lab \\
\hline 5 & Maria Ulfah & 34 & $\mathrm{P}$ & 10 Tahun & QHSE \\
\hline 6 & Yunia & 28 & $\mathrm{P}$ & 3 Tahun & Operational \\
\hline 7 & Dewi Sri Purnama & 29 & $\mathrm{P}$ & 5 Tahun & Ops - Lab \\
\hline 8 & Indah Budiarti & 29 & $\mathrm{P}$ & 3 Tahun & Operational \\
\hline 9 & Elda & 27 & $\mathrm{P}$ & 3 Tahun & Ops - Sertifikat \\
\hline 10 & Yuman Darmansyah & 24 & $\mathrm{~L}$ & 4 Tahun & GA \\
\hline 11 & M. Ramadhan Noor & 24 & $\mathrm{~L}$ & 1 Tahun & GA \\
\hline 12 & Wijayanti Sulistiani & 23 & $\mathrm{P}$ & 4 Tahun & Ops - Lab \\
\hline 13 & Syaiful Fajar & 28 & $\mathrm{~L}$ & 2 Tahun & GA \\
\hline 14 & Ahmad Hidayat & 43 & $\mathrm{~L}$ & 17 Tahun & GA \\
\hline 15 & Siti Sarah & 31 & $\mathrm{P}$ & 6 Tahun & Adm GA \\
\hline & & & & JIEB, Jilid 5, No 3, November 2019 & ISSN Online 2615-2134
\end{tabular}




\section{Diskusi}

Berdasarkan data yang telah disajikan sebelumnya, di bawah ini merupakan analisis peneliti berdasarkan hasil dimensi dan parameter yang telah diterapkan sebelumnya:

1. Pemberdayaan Sumber Daya Manusia di PT. CARSURIN

a. Kepercayaan

Kepercayaan di antara karyawan PT. CARSURIN di bangun dengan salah satu cara menciptakan iklim kekeluargaan. Dalam konteks budaya timur seperti Indonesia, hubungan baik atau kekeluargaan menjadi salah satu faktor penting sebagai pendorong bagi karyawan untuk menambah kemampuan kerja dan mengembangkan diri dalam pekerjaan. Perusahaan memberi iklim kekeluargaan yang menambah tingkat kepercayaan pada setiap karyawan. Hasil uraian wawancara tentang tingkat kepercayaan dari 15 informan kepada perusahaan masih standar dan biasa saja karena perusahaan memberdayakan karyawannya belum secara maksimal, tingkat kepercayaan kepada atasan dan rekan kerja informan sangat percaya karena tujuannya sama untuk mempermudah dan memperlancar kegiatan perusahaan. 1 informan yang menurutnya tingkat kepercayaan krpada rekan kerja 60\%, karena kepercayaan haru berlandaskan kejujuran dan transparasi.

\section{b. Motivasi}

Motivasi sebagai dorongan suatu gerak jiwa dan perilaku seseorang untu berbuat. Dari hasil wawancara informan/karyawan PT. Carsurin Banjarbaru, bahwa motivasi bekerja yang utama sangat dipengaruhi oleh kebutuhan hidup atau memenuhi kebutuhan hidup untuk menafkahi keluarga, motivasi berlandaskan kenyamanan lingkungan kerja serta pimpinan yang memberikan motivasi dan mengayomi bawahannya, motivasi kerja sangat berpengaruh mendapatkan salary dan reward serta jenjang karir. Hal ini sangat diperlukan bagi karyawan untuk tetap semangat dalam bekerja.

\section{c. Pengambilan Keputusan}

Pengambilan keputusan hasil pemecahan dalam suatu masalah yang harus dihadapi dengan tegas. Karyawan PT. Carsurin Banjarbaru ketika menghadapi suatu permasalah dalam pekerjaanya bisa langsung dikonsultasikan dengan pimpinan mencari solusi/jalan keluar masalah agar segera terselesaikan, ada karyawan yang berkonsultasi kepada rekan kerjanya yang diyakini bisa membantu memberikan solusi penyelesaian masalah, dan ada karyawan yang mampu menyelesaikan sendiri permasalahan ditempat kerjanya, dengan menyelesaikan suatu permasalahan dengan baik dan bijak, mau belajar untu memperbaiki kualitas diri dan berusaha tidak mengulangi kesalahan yang sama.

\section{d. Stagnan Mind-Sets}

Stagnan Mind-Sets adalah membantu karyawan keluar dari kemandegan cara berpikir, untuk mengambil resiko dan mencoba sesuatu yang baru. Karyawan PT. Carsurin Banjarbaru, mengambil resiko atau sesuatu yang baru bila dalam perjalanan karir dalam waktu lama merasa tidak ada peningkatan dan pemberdayaan bagi karyawan, yang di lakukan karyawan mencari tempat kerja baru dan pengalaman yang baru, mencari pekerjaan yang lebih baik. karyawan PT. Carsurin melakukan komunikasi dan berkonsultasi agar bisa dilakukan pelatihan-pelatihan dan training untuk kemajuan pemberdayaan SDM/karyawan yang menunjang kinerja karyawannya. 


\section{Potensi Human capital pada PT. CARSURIN}

Sebagaimana telah diungkapkan dalam analisis data, mengenai potensi Human capital yang ada di PT CARSURIN telah di dapat gambaran bahwa PT CARSURIN memiliki potensi Human capital cukup besar, namun masih memerlukan upaya-upaya strategis yang dapat mengoptimalkan potensi tersebut, khususnya dalam beberapa dimensi berikut :

a. Pengetahuan (Knowlwedge)

Hasil dari wawancara informan seluruh informan mengakui dengan benar bahwa mereka dibandingkan sebelum bekerja dan sesudah bekerja di PT. Carsurin ada peningkatan pengetahuan di bidang ilmu masing-masing, Pengetahuan karyawan PT. Carsurin Banjarbaru bertambah dan berkembang di proses pemeriksaan batu bara dan pelayanan jasa, pengetahuan sistem manajemen kerja dan team kerja yang solid, hal ini sangat diperlukan untuk meningkatka pengetahuan karyawan setiap departemen/divisi yang menunjang kerja mereka selesai tepat waktu.

b. Keahlian (Expertise)

Keahlian yang dimiliki karyawan PT. Carsurin Banjarbaru sebagian besar sudah cukup menunjang kinerja di bidangnya masing-masing, namun beberapa karyawan mempunyai keahlian masih belum menunjang pekerjaannya karena penempatan posisi kerja yang tidak sesuai, ada 1 karyawan yang menurutnya keahlian yang dimiliki belum cukup menunjang pekerjaan karena tidak akan puas akan ilmu pengetahuan dimiliki mau terus belajar dan berkembang, karyawan PT Carsurin sangat perlu di lakukan pelatihapelatihan, pengembangan/training untuk meningkatkan kualitas kerja karyawan PT. Carsurin Banjarbaru dalam mengoptimalkan Human capital.

c. Kemampuan (Ability)

Kemampuan yang dimiliki karyawan PT. Carsurin Bnjarbaru sudah sesuai dengan minat dan kemampuan di posisi pekerjaannya, sehingga mempermudah bagi mereka untuk menyelesaikan tugas-tugas denagn tepat waktu. Ada beberapa karyawan yang memiliki kemampuan belum sesuai minat dan kemampuan di bidang kerjanya, karyawan tersebut tetap mau belajar untuk meningkatkan kemampuan untuk menguasai pekerjaan saat ini, bentuk tanggung jawab dalam penyelesaian tugas. Kemampuan yang dimiliki karyawan sangat memberikan input bagi perusahaan, hal ini perlu dilakukan peningkatan kemampuan terhadap pemberdayaan SDM atau karyawan dalam mengopyimalkan Human capital pada PT. Carsurin Banjarbaru.

\section{d. Keterampilan (Skill)}

Keterampilan yang dimiliki karywan PT. Carsurin Banjarbaru sudah memberikan kontribusi yang baik bagi perusahaan, keterampilan yang memberikan kontribusi mengenai tugas dan tanggung jawab dibidang kerjanya masing-masing, namun ada beberapa karyawan yang meyakini dirinya belum maksimal memberikan kontribusi terhadap perusahaan karena masih perlu menambah keterampilan yang mampu membantu secara maksiaml saat rekan kerja memerlukan bantuannya. Berkaitan dengan keterampilan karyawan masih perlu adanya pembenahan dan pengembangan pemberdayaan sumber daya manusia dalam mengoptimalkan Human capital di PT. Carsurin Banjarbaru, sangat diperlukan pelatihan atau training terhadap karyawan untuk menunjang kinerja dan dapat berkembang seiring dengan perkembangan teknologi yang canggih, serta memberikan input yang baik bagi PT. Carsurin Banjarbaru. 


\section{Kesimpulan dan Keterbatasan Penelitian}

1. Dari hasil kajian implementasi pemberdayaan Sumber Daya Manusia di PT. CARSURIN Banjarbaru: dimensi pemberdayaan yang telah di implementasikan dengan baik adalah motivasi dan pengambilan keputusan, dimensi yang sedang dilakukan namun masih perlu peningkatan adalah kepercayaan, dimensi yang paling lemah serta perlu mendapat perhatian lebih adalah dimensi stagnan mind-sets.

2. Dari hasil kajian mengenai potensi Human capital, ditemukan bahwa perusahaan memiliki potensi Human capital yang cukup besar, dimensi pengetahuan dan kemampuan, dimensi yang sedang dilakukan namun masih memerlukan upaya-upaya yang dapat mengoptimalkan potensi tersebut, dibidang keahlian dan keterampilan.

3. Dari hasil kajian mengenai faktor-faktor yang menghambat atau menjadi tantangan dalam Pemberdayaan Sumber Daya Manusia dalam mengoptimalkan potensi Human capital hal yang menjadi hambatan atau tantangan dalam pemberdayaan SDM, apabila dikategorikan berdasarkan penyebab sekaligus langkah untuk mengatasinya/memperbaikinya adalah:

a. Manajemen PT. Carsurin Banjarbaru perlu memiliki konsep dan paradigma yang jelas mengenai dimensi pemberdayaan sumber daya manusia dan pemahaman tentang Human capital, yang kemudian perlu diikuti dengan implementasi yang diwajibkan karyawannya mengikuti pelatihan dan training untuk menunjang kinerja dan meningkatkan keterampilan masing-masing karyawan.

b. PT. Carsurin Banjarbaru perlu meningkatkan peran kepercayaan kepada karyawan, yang menjadi ujung tombak kemajuan perusahaan agar tetap berkembang dan mampu bersaing dengan perusahaan khususnya pelayanan dan jasa. Implementasi yang perlu dilakukan oleh perusahaan memberikan pemberdayaan secara maksimal dan merata keseluruh karyawan dengan memenuhi fasilitas yang menungjang kinerja karyawan untuk memperlancar dan mempermudah tugas perusahaan.

4. Ada 4 (Empat) hal yang memerlukan perbaikan dalam implementasi pemberdayaan SDM khususnya dalam upaya mengoptimalkan potensi Human capital, yaitu :

a. Pertama, tingkat kepercayaan peran perusahaan dalam pemberdayaan, masih satandar dan biasa-biasa saja, belum merasakan pemberdayaan yang layak untuk karyawan. Perhatian dan tindakan PT. Carsurin dalam memberikan peran kepercayaan perlu dilakukan pemberdayaan karyawan yang meliputi :

1) Menjalin komunikasi yang baik dari pimpinan dan bawahan, sehingga karyawan merasa di hargai dan diberdayakan.

2) Memberikan fasilitas yang memadai sesusai kebutuhan di bidang kerja karyawan.

3) Perusahaan memberikan pengembangan pelatihan dan training untuk menunjang kualitas dan menambah keterampilan karyawan.

b. Kedua untuk memberikan motivasi terhadap karyawannya peran perhatian yang perlu dilakukan PT. Carsurin adalah:

1) Menciptakan lingkungan kerja yang kondusif, nyaman dan kekeluargaan.

2) Memberikan salary dan reward untuk karyawan atas prestasi kerjanya.

3) Pemimpin yang baik, adil dan bijaksana dan punya loyalitas yang tinggi kepada karyawannya.

c. Ketiga pengambilan keputusan sangat diperlukan bagi PT. CARSURIN Banjarbaru memberikan peran perhatian pengambilan keputusan bagi karyawannya adalah:

1) Pemimpin menerima konsultasi, saran dan masukan karyawannya.

2) Pemimpin membantu karyawan yang sedang mengalami kesulitan/permasalahan. 
d. Keempat stagnan mind-sets yang harus dilakukan PT. Carsurin terhadap karyawan untuk melakukan hal-hal yang baru dan mencoba sesuatu yang baru untuk menambah pengetahuan dan keterampilannya adalah :

1) PT. Carsurin mengadakan pelatihan dan training memberdayaan karyawannya guna memperoleh pengetahuan dan menambah keterampilan yang baru, untuk menunjang kinerja karyawan.

2) PT. Carsurin perlu menjadwalkan seminar dalam waktu 1 bulan, $2 X$ pertemuan. Bisa dilakukan seminar untuk karyawan mdnambah ilmu pengetahuan untuk meningkatkan kerja karyawan.

Dari kesimpulan hasil kajian di atas, berikut ini beberapa rekomendasi untuk manajemen perusahaan PT. CARSURIN:

1. Pemberdayaan SDM merupakan kebijakan manajemen, oleh karena itu manajemen perlu memahami 4 (empat) dimensi dari pemberdayaan SDM).

2. Manajemen perusahaan khususnya Human Resources Departement (HRD) perlu memahami dan melihat secara utuh potensi Human capital.

3. Manajemen PT. CARSURIN secara serius perlu merespon perkembangan dalam dunia bisnis, khususnya kompetisi yang semakin ketat antar negara, perusahaan dan individu, dengan cara meningkatkan kompetensi para karyawannya.

4. Manajemen perusahaan perlu memiliki paradigma dan pemahaman bersama mengenai Human capital, dan berbagai dimensi dari Human capital.

5. Iklim atau suasana kekeluargaan yang selama ini telah dimiliki PT. CARSURIN sudah sangat baik dan cocok dengan budaya orang Indonesia, dapat terus dipertahankan dan dikembangkan untuk menjadi budaya perusahaan sejauh mendukung efektifitas pencapaian tujuan perusahaan dan menjadi motivasi positif bagi karyawan sehingga mereka tetap produktif.

\section{DAFTAR PUSTAKA}

Arikunto, Suharsimi, 2010, Prosedur Penelitian Suatu Pendekatan Praktik, Jakarta : Rineka Cipta.

Assen, Marcel van, Gerben van den Berg \& Paul Pietersma, 2009, Key Management Models, The 60+ Models Every Manager Needs to Know, 2nd edition, United Kingdom, Pearson Education Limited.

Baron, Angela and Michael Armstrong, 2007, Human capital Management, Achieving Added Value Through People, USA : Kogan Page Limited.

Gaol, Chr. Jimmy L., 2014, A to Z Human capital Manajemen Sumber Daya Manusia, Jakarta : PT. Grasindo.

Indrawan, Rully dan Poppy Yaniawati, 2014, Metodologi Penelitian, Bandung : Refika Aditama.

Lembaga Administrasi Negara, 2008, Pemberdayaan Sumber Daya Manusia, Jakarta : LAN.

Mayo, Andrew, 2008, So what's the Difference between Human capital and Human Resources?, West London Branch : CIPD.

Moleong, Lexy J., 2007, Metodologi Penelitian Kualitatif, Bandung : Penerbit PT Remaja Rosdakarya.

Mulyono, 2008, Manajemen Administrasi dan Organisasi Pendidikan, Yogyakarta : Ar-Ruzz Media.

Rarasputri, Mia, 2011, Human capital Management. http://www.slideshare.net/ miararasputri/ human-capital-management-9399610, [06 Juli 2015]. 
Sugiyono, 2012, Metode Penelitian Kuantitatif Kualitatif dan R \& D, Bandung : CV Alfabeta. Suharto, Edi, 2009, Membangun Rakyat, Memberdayakan Rakyat, Bandung : PT Refika Aditama.

Yamoah, Emmanuel Erastus, 2014, The Link between Human Resource Capacity Building and Job Performanc, International Journal of Human Resource Studies, Vol. 4, No. 3. 